\title{
Association Between Annual Change in FEV1 and Comorbidities or Impulse Oscillometry in Chronic Obstructive Pulmonary Disease.
}

Hiroyuki Sugawara

Sugawara Internal Medicine and Respiratory Clinic

Atsushi Saito ( $\nabla$ a-saito@sapmed.ac.jp )

Sapporo Medical University https://orcid.org/0000-0003-3430-884X

Saori Yokoyama

Sapporo Medical University

Kazunori Tsunematsu

Sugawara Internal Medicine and Respiratory Medicine

Hirofumi Chiba

Sapporo Medical University

\section{Research}

Keywords: Chronic obstructive pulmonary disease, Impulse oscillometry system, Pulmonary function test, COPD Assessment Test, St. George's Respiratory Questionnaire

Posted Date: November 8th, 2021

DOI: https://doi.org/10.21203/rs.3.rs-1029683/v1

License: (1) This work is licensed under a Creative Commons Attribution 4.0 International License.

Read Full License 


\section{Abstract}

\section{Background:}

Chronic obstructive pulmonary disease (COPD) is characterized by persistent respiratory symptoms and airflow limitation. The decline in forced expiratory volume in one second $\left(\mathrm{FEV}_{1}\right)$ is considered to be one of the most important outcome measures for evaluating disease progression. However, the only intervention proven to improve COPD prognosis is smoking cessation. This study therefore investigated the factors associated with annual $\mathrm{FEV}_{1}$ decline in COPD.

\section{Methods:}

This retrospective study followed up 65 patients treated for COPD for 5 years: 13 current smokers and 52 former smokers, 25 with pneumonia, 24 with asthma, 18 with cancer, and 17 with cardiovascular disease. The patients were divided into groups based on clinical cut-off parameters of the impulse oscillometry system (IOS): 11 high and 54 low R5, 8 high and 57 low R20, 21 high and 44 low R5-R20, 26 high and 39 low X5, 38 high and 27 low Fres, and 36 high and 29 low AX. We investigated whether the decline in FEV 1 was associated with comorbidities and IOS parameters.

\section{Results:}

The annual change in $\mathrm{FEV}_{1}$ over 5 years was significantly affected by smoking status (current -66.2 $\mathrm{mL} /$ year vs former $-5.7 \mathrm{~mL} /$ year, $\mathrm{p}<0.01$ ), pneumonia (with $-31.5 \mathrm{~mL}$ /year vs without $-8.9 \mathrm{~mL} /$ year, $\mathrm{p}<$ 0.05 ), asthma (with $-30.2 \mathrm{~mL} /$ year vs $-10.8 \mathrm{~mL} /$ year, $\mathrm{p}<0.01$ ), but not by cancer and cardiovascular disease. In the groups defined by IOS results, only the high AX group had significantly more annual decline in $\mathrm{FEV}_{1}$ and $\% \mathrm{FEV}_{1}$ than the low $\operatorname{AX}$ group $(-22.1$ vs $-12.8, \mathrm{p}<0.05$ and -0.20 vs $0.40, p<0.05$, respectively).

\section{Conclusions:}

Smoking cessation, prevention of pneumonia, and asthma control could reduce FEV F $_{1}$ decline in COPD. AX might be a suitable parameter to predict the prognosis of COPD patients.

\section{Background}

Chronic obstructive pulmonary disease (COPD), which is characterized by persistent respiratory symptoms and airflow limitation caused by a mixture of small airway disease and parenchymal destruction, is now one of the top three cause worldwide and a major cause of chronic morbidity and mortality [1]. To evaluate disease progression, one of the most important outcome biomarkers is the decline in forced expiratory volume in one second $\left(\mathrm{FEV}_{1}\right)$ [2-5]. Cigarette smoking is well known as the most common risk factor for COPD; smokers have a higher prevalence of respiratory symptoms and abnormalities of respiratory function, a greater annual rate of decline in $\mathrm{FEV}_{1}$, and higher mortality than 
non-smokers [6]. Smoking cessation is the only intervention that has conclusively been shown to alter the rate of decline in $\mathrm{FEV}_{1}$ [7]. Long acting muscarine antagonist (LAMA) and long acting $\beta 2$ agonist (LABA) are now used for the treatment of COPD, but there are few data assessing the effects of smoking cessation in patients taking these drugs.

COPD often coexists with other diseases (comorbidities), such as pneumonia, asthma, cancer, and cardiovascular disease, that may have a significant impact on prognosis [8], but the impact of these comorbidities on $\mathrm{FEV}_{1}$ decline requires further investigation. Exacerbations have negative impacts on respiratory function and lead to worsening of the chronic progressive course of this disease [9], and pneumonia is a known cause of exacerbation, but few studies have investigated the relationship between episodes of pneumonia and annual decline of $\mathrm{FEV}_{1}$ in COPD. The prognosis of ACO (asthma-COPD overlap) patients is controversial [10-12]. Cancer has a great impact on the quality of life (QOL) and prognosis of COPD patients [13], and reduction in $\mathrm{FEV}_{1}$ is strongly associated with a higher incidence of atrial fibrillation and heart failure [14], but there have been few studies on how much cancer and cardiovascular disease affect respiratory function.

The impulse oscillometry system (IOS) can be used to assess the function of large and small airways. It is a noninvasive device which assesses respiratory function by the forced oscillation technique [15-17]. Our previous work revealed that phenotypic difference in IOS parameters could be associated with the efficacy of inhaled corticosteroids (ICS) in asthma and cough variant asthma [18, 19]. We therefore hypothesized that in COPD, IOS may have the potential to detect airway obstruction earlier than spirometry.

We therefore carried out this study to clarify how the rate of $\mathrm{FEV}_{1}$ decline is affected by treatment with LAMA or/and LABA in COPD patients who quit smoking compared with those who did not, to investigate the relationship between respiratory function and COPD comorbidities, and to investigate whether baseline IOS parameters could predict future decline of respiratory function in patients with COPD.

\section{Methods}

\section{Participants and treatment}

This was a single-center retrospective observational study. Patients with COPD treated in the clinic between January 2012 and December 2015 were included in the study. All patients presented with chronic dyspnea, chronic cough or sputum production, and a history of smoking, and were diagnosed by confirming the presence of persistent airflow limitation based on post-bronchodilator $\mathrm{FEV}_{1} /$ forced vital capacity $(F V C)<0.70$ [20]. Patients were assessed by spirometry and IOS and followed up for 5 years. Patients were excluded if treatment was interrupted during the follow-up period or if they were transferred to another hospital. 
At the first visit, demographic information, including gender, age, height, weight, smoking history, medical history and any medications, and information on pulmonary symptoms (modified Medical Research Council [mMRC] Dyspnea Scale and COPD Assessment Test [CAT]), and comorbidities were collected.

Patients diagnosed with COPD were treated with LAMA, LABA, and added ICS if they had an asthma phenotype, according to the Global Initiative for Chronic Obstructive Lung Disease (GOLD) guidelines [21]. This study was conducted in accordance with the declaration of Helsinki and was approved by the institutional ethical committee of Sapporo Medical Association. The experimental protocols and the purpose of the research were explained to all participants and informed consent was obtained in the form of opt-out on the web-site.

\section{Measurements of IOS and pulmonary function}

IOS was measured using a commercially available impulse oscillometry device (MasterScreen IOS, Jaeger, Germany) according to the manufacturer's recommendations [17]. The resistance at $5 \mathrm{~Hz}$ (R5: indicating total airway resistance), resistance at $20 \mathrm{~Hz}$ (R20: representing central airway resistance), difference between R5 and R20 (R5-R20: index of the small airways), reactance at $5 \mathrm{~Hz}$ (X5: relating to compliance), resonant frequency (Fres), and integrated area of low frequency $X$ ( $A X$ ) were evaluated [2224]. The use of Fres and $A X$ has been proposed to detect the degree of obstruction in the peripheral airways $[15,22,25]$.

After measuring IOS, a pulmonary function test was performed using spirometry (MasterScreen IOS, Jaeger, Germany). The tests were performed in this order to prevent any negative effects of forced expiration on the airway. The percentage predicted forced vital capacity $(\% \mathrm{FVC})$, percentage predicted forced expiratory volume in one second $\left(\% \mathrm{FEV}_{1}\right), \mathrm{FEV}_{1} / \mathrm{FVC}$ ratio, percentage predicted maximal midexpiratory flow (\%MMEF), and percentage predicted peak expiratory flow (\%PEF) were assessed.

For parameters of IOS, only a few predicted values are available for Caucasians according to Vogel \& Smidt [26] and there are no defined reference values for COPD. We adopted cut-off IOS values for COPD based on previous reports [25, 27-31], as follows: R5 $=0.39, \mathrm{R} 20=0.27, \mathrm{R} 5-\mathrm{R} 20=0.10, \mathrm{X} 5=-0.13$, Fres $=17.7$, and $A X=0.55$. If the measured value was higher or lower than the cut-off value, it was recorded as a high or low IOS parameter, respectively.

\section{Assessment of dyspnea and QOL}

We assessed the two most widely used measures of symptoms, according to GOLD [8]. Dyspnea was evaluated according to the modified British Medical Research Council (mMRC) scale. A questionnaire scale was considered adequate to assess symptoms. The $\mathrm{mMRC}$ is a grading scale from $0-4$ which relates well to other measurements of health status [32].

The COPD Assessment Test (CAT ${ }^{\mathrm{TM}}$ ) is an eight-item unidimensional measure of health status impairment in COPD [33]. This score ranges from 0-40 and correlates closely with St. George's 
Respiratory Questionnaire (SGRQ) [34].

\section{Retrospective observation of annual change in $\mathrm{FEV}_{1}$}

For patients who were current smokers, we explained the need for smoking cessation to patients diagnosed with COPD, instructed them to quit smoking, and provided smoking cessation treatment if necessary. The patients' respiratory function was retrospectively observed for 5 years. Baseline respiratory function and smoking status were recorded at least 3 months after the start of COPD treatment. Spirometry was performed every 6 months in patients who inhaled LAMA or/and LABA the morning of the test, and the annual change in values and \% predicted was calculated.

\section{Statistical analysis}

Numeric variables are expressed as means \pm standard error of mean. Differences between two groups were assessed using unpaired two tailed t-tests. Categorical variables were compared using chi-square tests. A p value $<0.05$ was considered statistically significant. Microsoft Excel 2016 (Microsoft Corporation, the USA), Excel Statistical Program File (ystat2008.xls, Igakutosho-shuppan Ltd., Tokyo, Japan), and GraphPad Prism v8 (GraphPad, Inc., San Diego, CA, the USA) were used for data analysis and graph generation.

\section{Result}

\section{Selection of participants}

We screened 97 patients with COPD during the inclusion period. Of these, 23 were excluded due to treatment interruption (in $<1$ year [n=13], 1 to $<2$ years [n $=3$ ], 2 to $<3$ years [ $=5$ ], or in 3 to $<4$ years [n $=$ 2]) and 9 patients were excluded due to hospital transfer (for respiratory failure [n $=5]$, for cancer [n $=2]$, or for pneumonia [ $n=2])$. After exclusions, 65 patients with COPD were assessed by spirometry and IOS and followed up for 5 years (Fig. 1).

Smoking status and comorbidities are described in Fig. 1. Patients were current smokers $(n=13$, comprising 3 continuous smokers and 10 intermittent smokers) or former smokers ( $n=52$, including patients who quit smoking at diagnosed with COPD). Recorded comorbidities were pneumonia $(n=25$ : hospital admission $n=9$, outpatient $n=16$ ), bronchial asthma $(n=24$ : high dose ICS $n=12$, intermediate ICS $n=12$, low dose ICS $n=0)$, cancer $(n=18$ : lung cancer $n=7$, colon cancer $n=4$, stomach cancer $n=2$, prostate cancer $n=2$, laryngeal cancer $n=1$, esophageal cancer $n=1$, bladder cancer $n=1$ ), cardiovascular disease $(n=17$ : arrhythmia $n=9$, aortic aneurysm $n=5$, arterial sclerosis obliterans $n=4$, cerebral infarction $n=3$, ischemic heart disease $n=1$ ). Some patients had more than one disease.

The baseline characteristics of the 65 participants and their spirometry and IOS 5 years after treatment are shown in Table 1. $\mathrm{FEV}_{1}$ and $\mathrm{FEV}_{1} / \mathrm{FVC}$ significantly decreased between baseline and 5 years but there 
were no significant changes in \% $\mathrm{FEV}_{1}, \% \mathrm{FVC}$, \% MMEF, or \%PEF. Except R20, all IOS parameters were significantly reduced at 5 years after treatment.

\section{Annual Change In Fev And los In Smoking Status}

The annual change in $\mathrm{FEV}_{1}$ ( $\mathrm{mL} /$ year) across 5 years varied widely, with a mean \pm standard deviation (SD) of $-17.8 \pm 32.4$ and a range from -142.0 to 34.0 (Fig. 2). Comparing changes over time in current and former smokers, $\mathrm{FEV}_{1}$ or $\% \mathrm{FEV}_{1}$ were both significantly lower at 4 and 5 years after treatment in current smokers (Fig. 3). Comparisons between these cohorts are presented in Table 2. At baseline there was no significant difference in $\mathrm{FEV}_{1}$ between current and former smokers $(p=0.44)$ but 5 years after treatment it was lower in current smokers $(p<0.05)$. The annual changes in $\mathrm{FEV}_{1}$ and $\% \mathrm{FEV}_{1}$ were significantly different between current and former smokers $(-66.2 \mathrm{~mL} /$ year vs $-5.7 \mathrm{~mL} /$ year; $\mathrm{p}<0.01$ and $-2.1 \mathrm{~mL} /$ year vs $0.6 \mathrm{~mL} /$ year; $p<0.01$, respectively). No IOS parameter differed between current and former smokers (Table 2).

\section{Characteristics, the annual change in FEV 1 , and IOS in patients with and without comorbidities}

Table 2 describes the characteristics of patients with and without each COPD comorbidity. There were no differences in age, sex, BMI, smoking history, total IgE, and CAT in the groups defined by presence or absence of any of the comorbidities. Patients with pneumonia, asthma, or cancer had higher neutrophil counts than those without each disease respectively. The asthmatic group included higher numbers of current smokers and had higher eosinophil counts than the non-asthmatic group (10:14 vs 3:38; $p<0.01$ and 248.2 vs $179.4 ; p<0.05$, respectively). In the patients with pneumonia, the mMRC was higher than in those without pneumonia ( 1.5 vs $1.1, p<0.05)$. CAT scores did not differ between any group.

At almost every annual timepoint, $\mathrm{FEV}_{1}$ and $\% \mathrm{FEV}_{1}$ were significantly lower in patients with pneumonia or asthma than those without, but there were no differences in patients with or without cancer or cardiovascular disease (Fig. 4). There was significantly more annual decline in $\mathrm{FEV}_{1}$ in the pneumonia group than in the non-pneumonia group $(-31.5$ vs $-8.9, p<0.01)$ and in the asthma group than in the non-asthma group $(-30.2$ vs $-10.8, p<0.05)$. The annual decline in $\% \mathrm{FEV}_{1}$ was notable in patients with pneumonia ( -0.49 vs 0.44 in patients without pneumonia, $p<0.01)$ and asthma $(-0.53$ vs 0.42 in patients without asthma, $\mathrm{p}<0.01)$. However, there was no change in annual decline in FEV1 and \%FEV 1 in patients with cancer and cardiovascular disease (Table 2).

Similar trends according to comorbidity were seen in IOS. Patients with pneumonia or asthma had higher R5, R5-R20, Fres, and AX values than those without, while the presence or absence of cancer or cardiovascular disease did not have a significant effect on the IOS results.

Characteristics, the annual change in $\mathrm{FEV}_{1}$, and the rate of comorbidity in groups classified by IOS parameters 
COPD patients were divided into high or low groups for each baseline IOS parameter and the differences in baseline characteristics, annual decline in $\mathrm{FEV}_{1}\left(\% \mathrm{FEV}_{1}\right)$, and comorbidity rates compared (Table 3 ).

There was no significant difference in any baseline characteristic based on IOS parameters, except that the high R5 group had a higher age $(74.6$ vs $68.6, p<0.05)$ and higher proportion of males $(6: 5$ vs $47: 7, p$ $<0.05)$. The mMRC of the high R5-R20 group, the low X5 group, the high Fres group, and the high AX group was significantly higher than the corresponding other group in each case (1.5 vs $1.2, p<0.05 ; 1.5$ vs $1.2, p<0.05 ; 1.4$ vs $1.1, p<0.01 ; 1.4$ vs $1.1, p<0.05$, respectively). The CAT score was significantly higher only in the low X5 group and the high Fres group (7.5 vs 4.9, $p<0.05,7.3$ vs $4.3 p<0.01$, respectively).

For the annual decline in $\mathrm{FEV}_{1}$ and \%FEV 1 , only the high $\mathrm{AX}$ group was significantly lower than the low $\mathrm{AX}$ group ( -22.1 vs $-12.8, p<0.05$ and -0.20 vs $0.40, p<0.05$, respectively).

The ratios of each comorbidity were also compared between the groups classified by IOS values. The high R5-R20 group, the low X5 group, the high Fres group, and the high AX group had significantly higher numbers of patients with pneumonia than the corresponding other group (13:8 vs 13:31, $p<0.05 ; 15: 11$ vs $11: 28, p<0.05 ; 20: 18$ vs $6: 21, p<0.05 ; 19: 17$ vs $7: 22, p<0.05$, respectively). For asthma, significant differences were observed between the groups based on R20 (6:2 vs 18:39, $p<0.05)$, X5 (14:12 vs 10:29, $p<0.05)$, Fres (19:19 vs 5:22, $p<0.05)$, and $A X(20: 16$ vs $4: 25, p<0.01)$. There were no differences in the ratios of patients with cancer or cardiovascular disease between the groups defined by any IOS parameter.

\section{Discussion}

In this observational study, we demonstrated that smoking cessation with proper treatment could prevent decline in $\mathrm{FEV}_{1}$, that pneumonia and asthma as comorbidities might result in decline in lung function, and that the IOS parameter AX at baseline can predict future decline in $\mathrm{FEV}_{1}$ in patients with COPD.

Recent studies have shown that the rate of decline in $\mathrm{FEV}_{1}$ in properly treated patients with COPD varies widely from rapid to relatively modest decline in lung function over a 3-5 year period $[5,35]$. Because COPD patients who continue to smoke are at increased risk of marked progression compared with former smokers, smoking cessation is considered to be the most important tool in secondary prevention of FEV 1 decline. Many studies have compared FEV ${ }_{1}$ decline between smokers and former smokers $[2,5,36,37]$. In the present study, $\mathrm{FEV}_{1}$ in current smokers on LAMA and LABA treatment was reduced by $66.2 \mathrm{~mL}(2.1 \%)$ per year, far more than for former smokers, in which it was reduced by $5.7 \mathrm{ml}(+0.6 \%)$ per year. Since $80 \%$ of patients were former smokers, the overall $\mathrm{FEV}_{1}$ reduction rate was relatively low at $-17.8 \mathrm{~mL}(+0.06 \%)$ per year. Change in pulmonary function is considered to be suppressed by smoking cessation and appropriate treatment, which could improve the prognosis of patients with COPD. On the other hand, when IOS parameters were compared between current and former smokers, there were no differences, in agreement with a previous study [27]. Overall, in the present study smoking cessation and COPD therapy 
improved the prognosis of respiratory function as in previous studies, but could not be simply detected by IOS.

COPD often has various comorbidities related to smoking and aging, such as pneumonia, asthma, cancer, and cardiovascular diseases, and these negatively affect QOL and prognosis. Patients with a high frequency of exacerbations have a greater decline in $\mathrm{FEV}_{1}$ than those with a low frequency of exacerbations [9], and one of the causes of exacerbations is pneumonia. However, few studies have directly shown that pneumonia is associated with annual decline in $\mathrm{FEV}_{1}$. Our data showed that $F E V_{1}$ decline in patients with pneumonia was higher than those without pneumonia $(-31.5 \mathrm{~mL} /$ year vs -8.9 $\mathrm{mL} /$ year). This indicates that the prognosis for COPD patients with episodes of pneumonia may be poor. The link between COPD and pneumonia may be explained by airway inflammation caused by a viral or bacterial infection.

Regarding ACO, the prognosis is controversial $[10,11,38]$, so we examined changes in respiratory function over 5 years in COPD patients with or without asthma. We found that the $\% \mathrm{FEV}_{1}$ changed more in patients with ACO than in those with COPD alone; the annual decline in $\mathrm{FEV}_{1}\left(\% \mathrm{FEV}_{1}\right)$ in ACO was -30 $\mathrm{mL}(-0.53 \%)$ per year, compared with $-10.8 \mathrm{~mL}(0.42 \%)$ / year in COPD. This suggested that the prognosis for ACO could be poorer than that for COPD. Asthma-related airway inflammation in addition to COPD airway obstruction could have contributed to the decline in respiratory function.

Cancers other than lung cancer are often associated with COPD in the real world. However, while many studies report a strong relationship between reduction in $\mathrm{FEV}_{1}$ and the risk of lung cancer [39], there are few studies on the relationship between other cancers and FEV ${ }_{1}$ decline in COPD. In the present study, we found no differences in $\% \mathrm{FEV}_{1}$ over 5 years or annual change in $\mathrm{FEV}_{1}$ in patients with and without cancer. The subset of cases with lung cancer was too small to analyze separately, and it remains a possibility that there would be a significant difference in $\mathrm{FEV}_{1}$ in this cohort. This is a topic for future study.

Regarding cardiovascular disease, low $\mathrm{FEV}_{1}$ and airflow obstruction are associated with atrial fibrillation [14], coronary heart disease [40], heart failure [41], and stroke [42]. However, there have been few studies on whether cardiovascular diseases are associated with the annual decline in $\mathrm{FEV}_{1}$ in COPD patients. In this study, we found no significant difference in the decline of $\mathrm{FEV}_{1}$ between patients with or without cardiovascular disease. In terms of the combined effect of cardiovascular disease and cancer on COPD, the annual decline in respiratory function should be more fully investigated in future.

IOS can determine the mechanical properties of the lung and differentiate between large and small airway obstruction. It seems to be more sensitive and detect changes in lung function earlier than spirometry in COPD patients [43]. The IOS parameters R5, R5-R20, and X5 (and not R20) were shown to correlate with $\mathrm{FEV}_{1}$ in a cohort of COPD patients, and over 1 year the changes in X5 correlated with the changes in $\mathrm{FEV}_{1}$ [25]. Peripheral measurement by IOS (R5-R2O and X5) correlates with the SGRQ and mMRC scores [29]. Although there are no defined reference values for COPD, pathologically abnormal IOS 
cut offs have been proposed [27, 28]. Franz et. al. described subjects reporting respiratory symptoms with differing lung mechanics as measured by IOS, and in whom IOS had the potential to detect COPD pathology earlier than spirometry, and found that cut-off values in those with symptoms and meeting GOLD criteria were as follows: $\mathrm{R} 20=0.39, \mathrm{R} 20=0.27, \mathrm{R} 5-\mathrm{R} 20=0.10, \mathrm{X} 5=-0.13$, and $\mathrm{AX}=0.55[30]$. Separately, the cut-off value for Fres optimal to diagnose airflow obstruction in COPD patients was shown to be 1.77 [31]. In the present study, we classified the 65 COPD patients into two groups based on the above IOS cut-off values. The annual change of $\mathrm{FEV}_{1}$ was compared in each pair. In these groups classified according to IOS, COPD patients with high AX at baseline had significantly greater annual decline in $\mathrm{FEV}_{1}$ than patients with low $\mathrm{AX}(\mathrm{p}<0.05)$, indicating a correlation between $A X$ value and annual change in $\mathrm{FEV}_{1}$ over 5 years. R5-R20, X5, and Fres did not correlate with deterioration of pulmonary function. It is known that R5-R20 reflects obstruction in the distal airways [44] and X5 reflects the elastic components of the lung. On the other hand, $A X$ reflects changes in peripheral airway obstruction and reduction of lung compliance, which are typically observed in COPD [22, 45]. This may be why only $\mathrm{AX}$ was significantly associated with $\mathrm{FEV}_{1}$ decline.

The current study had some limitations. First, the study population was small, and the study design was retrospective. Although detailed comorbidities and the course of respiratory function was known by observation of COPD patients treated in a respiratory outpatient department, a prospective cohort study is needed in the future. Second, 32 of the 97 patients were excluded due to treatment interruption or hospital transfer. This is unlikely to have introduced bias, as there was no difference in the background characteristics of these patients compared to the 65 patients included in the study (data not shown). Third, since IOS is an emerging technique, the exact meaning and interpretation of its parameters are limited. Reference values in different populations have not yet been established. However, pathologically abnormal values were proposed for COPD patients in previous studies [30,31] and we used these to investigate the decline in $\mathrm{FEV}_{1}$.

\section{Conclusion}

This study showed that smoking cessation in addition to proper treatment was able to slow $\mathrm{FEV}_{1}$ decline in patients with COPD. Coexistence of pneumonia or asthma was associated with $\mathrm{FEV}_{1}$ decline, but cancer and cardiovascular disease were not. Smoking cessation, prevention of pneumonia, and asthma control could reduce FEV 1 decline and improve the prognosis on COPD. Our data suggest that baseline $A X$, which may detect and evaluate small airways and emphysema simultaneously, was the IOS parameter most related to the annual decline in $\mathrm{FEV}_{1}$ for $\mathrm{COPD}$ and may accurately predict prognosis in COPD patients.

\section{Abbreviations}

ACO: Asthma-COPD overlap; mMRC: modified British Research Council scale; CAT: COPD assessment test; LAMA: long acting muscarine antagonist; LABA: Iong acting $\beta 2$ agonist; ICS: Inhaled corticosteroid; 
FVC: Forced vital capacity; FEV1: Forced expiratory volume in one second; MMEF: Maximum midexpiratory flow; PEF: Peak expiratory flow; IOS: Impulse oscillometry system; R5: Resistance at $5 \mathrm{~Hz}$; R20: Resistance at $20 \mathrm{~Hz}$; R5-R20: the difference between R5 and R20; X5: Reactance at $5 \mathrm{~Hz}$; Fres: Resonance frequency; AX: Area of low-frequency reactance

\section{Declarations}

\section{Acknowledgments}

Not applicable.

\section{Funding}

This work was supported by Novartis Pharma Research Grants 2019 (to A. S.) and JSPS KAKENHI Grant Numbers 19 K23610 (to S. Y.).

\section{Availability of data and materials}

Please contact author for data requests.

\section{Competing interests}

None of the authors have a conflict of interest to declare.

\section{Ethics approval and consent to participate}

The study was approved by the ethics board of Sapporo Medical Association.

\section{Authors' contributions}

HS developed the study design, performed the experiments, analyzed and interpreted the data, and wrote the manuscript. AS contributed to data analysis and interpretation and manuscript revision. SY, KT, and $\mathrm{HC}$ assisted with data analysis and interpretation and supervised the statistical analysis. All authors read and approved the final manuscript.

\section{References}

1. Global Initiative for Chronic Obstructive Lung Disease. Global Strategy for Diagnosis, Management, and Prevention of Chronic Obstructive Pulmonary Disease 2021. Available from: https://goldcopd.org/.

2. Fletcher C, Peto R: The natural history of chronic airflow obstruction. Br Med J. 1: 1645-1648, 1977.

3. Tashkin DP, Celli B, Senn S, Burkhart D, Kesten S, Menjoge S, Decramer M, Investigators US: A 4-year trial of tiotropium in chronic obstructive pulmonary disease. N Engl J Med. 359: 1543-1554, 2008. 
4. Celli BR, Thomas NE, Anderson JA, Ferguson GT, Jenkins CR, Jones PW, Vestbo J, Knobil K, Yates JC, Calverley PM: Effect of pharmacotherapy on rate of decline of lung function in chronic obstructive pulmonary disease: results from the TORCH study. Am J Respir Crit Care Med. 178: 332-338, 2008.

5. Vestbo J, Edwards LD, Scanlon PD, Yates JC, Agusti A, Bakke P, Calverley PM, Celli B, Coxson HO, Crim C, Lomas DA, MacNee W, Miller BE, Silverman EK, Tal-Singer R, Wouters E, Rennard SI, Investigators $\mathrm{E}$ : Changes in forced expiratory volume in 1 second over time in COPD. N Engl J Med. 365: 1184-1192, 2011.

6. Kohansal R, Martinez-Camblor P, Agusti A, Buist AS, Mannino DM, Soriano JB: The natural history of chronic airflow obstruction revisited: an analysis of the Framingham offspring cohort. Am J Respir Crit Care Med. 180: 3-10, 2009.

7. Anthonisen NR, Connett JE, Murray RP: Smoking and lung function of Lung Health Study participants after 11 years. Am J Respir Crit Care Med. 166: 675-679, 2002.

8. Global Initiative for Chronic Obstructive Lung Disease. Global Strategy for Diagnosis, Management, and Prevention of Chronic Obstructive Pulmonary Disease 2020. Available from: https://goldcopd.org/.

9. Donaldson GC, Seemungal TA, Bhowmik A, Wedzicha JA: Relationship between exacerbation frequency and lung function decline in chronic obstructive pulmonary disease. Thorax. 57: 847-852, 2002.

10. Diaz-Guzman E, Khosravi M, Mannino DM: Asthma, chronic obstructive pulmonary disease, and mortality in the U.S. population. COPD. 8: 400-407, 2011.

11. Cosio BG, Soriano JB, Lopez-Campos JL, Calle-Rubio M, Soler-Cataluna JJ, de-Torres JP, Marin JM, Martinez-Gonzalez C, de Lucas P, Mir I, Peces-Barba G, Feu-Collado N, Solanes I, Alfageme I, Casanova C, Study C: Defining the Asthma-COPD Overlap Syndrome in a COPD Cohort. Chest. 149: 45-52, 2016.

12. Fu JJ, Gibson PG, Simpson JL, McDonald VM: Longitudinal changes in clinical outcomes in older patients with asthma, COPD and asthma-COPD overlap syndrome. Respiration. 87: 63-74, 2014.

13. Smith MC, Wrobel JP: Epidemiology and clinical impact of major comorbidities in patients with COPD. Int J Chron Obstruct Pulmon Dis. 9: 871-888, 2014.

14. Li J, Agarwal SK, Alonso A, Blecker S, Chamberlain AM, London SJ, Loehr LR, McNeill AM, Poole C, Soliman EZ, Heiss G: Airflow obstruction, lung function, and incidence of atrial fibrillation: the Atherosclerosis Risk in Communities (ARIC) study. Circulation. 129: 971-980, 2014.

15. Bickel S, Popler J, Lesnick B, Eid N: Impulse oscillometry: interpretation and practical applications. Chest. 146: 841-847, 2014.

16. Dubois AB, Brody AW, Lewis DH, Burgess BF, Jr.: Oscillation mechanics of lungs and chest in man. $J$ Appl Physiol. 8: 587-594, 1956.

17. Oostveen E, MacLeod D, Lorino H, Farre R, Hantos Z, Desager K, Marchal F, Measurements ERSTFoRI: The forced oscillation technique in clinical practice: methodology, recommendations and future developments. Eur Respir J. 22: 1026-1041, 2003. 
18. Sugawara H, Saito A, Yokoyama S, Tsunematsu K, Takahashi H: Comparison of therapeutic effects of inhaled corticosteroids on three subtypes of cough variant asthma as classified by the impulse oscillometry system. Respir Res. 20: 41, 2019.

19. Sugawara H, Saito A, Yokoyama S, Tsunematsu K, Chiba H, Takahashi H: A retrospective analysis of usefulness of impulse oscillometry system in the treatment of asthma. Respir Res. 21: 226, 2020.

20. Global Initiative for Chronic Obstructive Lung Disease. Chapter 2: Diagnosis and Initial assessment. Available from: http://www.goldcopd.org.

21. Global Initiative for Chronic Obstructive Lung Disease. Chapter 3 Evidence supporting prevention and Maintenance therapy. Available from: http://www.goldcopd.org.

22. Smith HJ RP, Goldman MD: Forced oscillation technique and impulse oscillometry. European Respiratory Monograph. 31: 72-105, 2005.

23. Goldman MD: Clinical application of forced oscillation. Pulm Pharmacol Ther. 14: 341-350, 2001.

24. Nieto A, Pamies R, Oliver F, Medina A, Caballero L, Mazon A: Montelukast improves pulmonary function measured by impulse oscillometry in children with asthma (Mio study). Respir Med. 100: 1180-1185, 2006.

25. Kolsum U, Borrill Z, Roy K, Starkey C, Vestbo J, Houghton C, Singh D: Impulse oscillometry in COPD: identification of measurements related to airway obstruction, airway conductance and lung volumes. Respir Med. 103: 136-143, 2009.

26. Vogel J SU: Impulse Oscillometry. Analysis of lung mechanics in general practice and clinic, epidemiological and experimental research. Frankfurt: PMI-Verlagsgruppe. 148-152: 1994.

27. Crim C, Celli B, Edwards LD, Wouters E, Coxson HO, Tal-Singer R, Calverley PM, investigators E: Respiratory system impedance with impulse oscillometry in healthy and COPD subjects: ECLIPSE baseline results. Respir Med. 105: 1069-1078, 2011.

28. Wei X, Shi Z, Cui Y, Mi J, Ma Z, Ren J, Li J, Xu S, Guo Y: Impulse oscillometry system as an alternative diagnostic method for chronic obstructive pulmonary disease. Medicine (Baltimore). 96: e8543, 2017.

29. Haruna A, Oga T, Muro S, Ohara T, Sato S, Marumo S, Kinose D, Terada K, Nishioka M, Ogawa E, Hoshino Y, Hirai T, Chin K, Mishima M: Relationship between peripheral airway function and patientreported outcomes in COPD: a cross-sectional study. BMC Pulm Med. 10: 10, 2010.

30. Frantz S, Nihlen U, Dencker M, Engstrom G, Lofdahl CG, Wollmer P: Impulse oscillometry may be of value in detecting early manifestations of COPD. Respir Med. 106: 1116-1123, 2012.

31. Liu Z, Lin L, Liu X: Clinical application value of impulse oscillometry in geriatric patients with COPD. Int J Chron Obstruct Pulmon Dis. 12: 897-905, 2017.

32. Bestall JC, Paul EA, Garrod R, Garnham R, Jones PW, Wedzicha JA: Usefulness of the Medical Research Council (MRC) dyspnoea scale as a measure of disability in patients with chronic obstructive pulmonary disease. Thorax. 54: 581-586, 1999. 
33. Jones PW, Harding G, Berry P, Wiklund I, Chen WH, Kline Leidy N: Development and first validation of the COPD Assessment Test. Eur Respir J. 34: 648-654, 2009.

34. Karloh M, Fleig Mayer A, Maurici R, Pizzichini MMM, Jones PW, Pizzichini E: The COPD Assessment Test: What Do We Know So Far?: A Systematic Review and Meta-Analysis About Clinical Outcomes Prediction and Classification of Patients Into GOLD Stages. Chest. 149: 413-425, 2016.

35. Nishimura M, Makita H, Nagai K, Konno S, Nasuhara Y, Hasegawa M, Shimizu K, Betsuyaku T, Ito YM, Fuke S, Igarashi T, Akiyama Y, Ogura S, Hokkaido CCSI: Annual change in pulmonary function and clinical phenotype in chronic obstructive pulmonary disease. Am J Respir Crit Care Med. 185: 44-52, 2012.

36. Anthonisen NR, Connett JE, Kiley JP, Altose MD, Bailey WC, Buist AS, Conway WA, Jr., Enright PL, Kanner RE, O'Hara P, et al.: Effects of smoking intervention and the use of an inhaled anticholinergic bronchodilator on the rate of decline of FEV1. The Lung Health Study. JAMA. 272: 1497-1505, 1994.

37. Kanner RE, Anthonisen NR, Connett JE, Lung Health Study Research G: Lower respiratory illnesses promote FEV(1) decline in current smokers but not ex-smokers with mild chronic obstructive pulmonary disease: results from the lung health study. Am J Respir Crit Care Med. 164: 358-364, 2001.

38. Lange P, Colak Y, Ingebrigtsen TS, Vestbo J, Marott JL: Long-term prognosis of asthma, chronic obstructive pulmonary disease, and asthma-chronic obstructive pulmonary disease overlap in the Copenhagen City Heart study: a prospective population-based analysis. Lancet Respir Med. 4: 454462, 2016.

39. Fry JS, Hamling JS, Lee PN: Systematic review with meta-analysis of the epidemiological evidence relating FEV1 decline to lung cancer risk. BMC Cancer. 12: 498, 2012.

40. Sin DD, Wu L, Man SF: The relationship between reduced lung function and cardiovascular mortality: a population-based study and a systematic review of the literature. Chest. 127: 1952-1959, 2005.

41. Agarwal SK, Heiss G, Barr RG, Chang PP, Loehr LR, Chambless LE, Shahar E, Kitzman DW, Rosamond WD: Airflow obstruction, lung function, and risk of incident heart failure: the Atherosclerosis Risk in Communities (ARIC) study. Eur J Heart Fail. 14: 414-422, 2012.

42. Truelsen T, Prescott E, Lange P, Schnohr P, Boysen G: Lung function and risk of fatal and non-fatal stroke. The Copenhagen City Heart Study. Int J Epidemiol. 30: 145-151, 2001.

43. Saadeh C, Saadeh C, Cross B, Gaylor M, Griffith M: Advantage of impulse oscillometry over spirometry to diagnose chronic obstructive pulmonary disease and monitor pulmonary responses to bronchodilators: An observational study. SAGE Open Med. 3: 2050312115578957, 2015.

44. Grimby G, Takishima T, Graham W, Macklem P, Mead J: Frequency dependence of flow resistance in patients with obstructive lung disease. J Clin Invest. 47: 1455-1465, 1968.

45. Eddy RL, Westcott A, Maksym GN, Parraga G, Dandurand RJ: Oscillometry and pulmonary magnetic resonance imaging in asthma and COPD. Physiol Rep. 7: e13955, 2019.

\section{Figures}




\section{7 patients with COPD treated in the clinic from January 2012 to December 2015}

\begin{tabular}{|l}
$\begin{array}{l}23 \text { patients were excluded due to treatment interruption } \\
\text { within } 1 \text { year, } n=13 \\
\text { within } 2 \text { years, } n=3 \\
\text { within } 3 \text { years, } n=5 \\
\text { within } 4 \text { years, } n=2\end{array}$ \\
$\quad \begin{array}{l}9 \text { patients were excluded due to transfer } \\
\text { for respiratory failure, } n=5 \\
\text { for cancer, } n=2 \\
\text { for pneumonia, } n=2\end{array}$ \\
with COPD for 5 year follow up were assessed by spirometry and IOS \\
tatus \\
urrent smoker $n=13$ (continuous smoker $n=3$, intermittent smoker $n=10$ ), former smoker $n=52$ \\
ties (There are overlaps in the number of each disease ) \\
oumonia $n=25$ (hospital admission $n=9$, outpatient $n=16$ ) \\
cerebral infarction $n=3$, ischemic heart disease $n=1$ )
\end{tabular}

Figure 1

Selection of participants. Of 97 patients diagnosed with COPD who treated the clinic between January 2012 and December 2015, 32 patients were excluded and 65 participated in this study. 


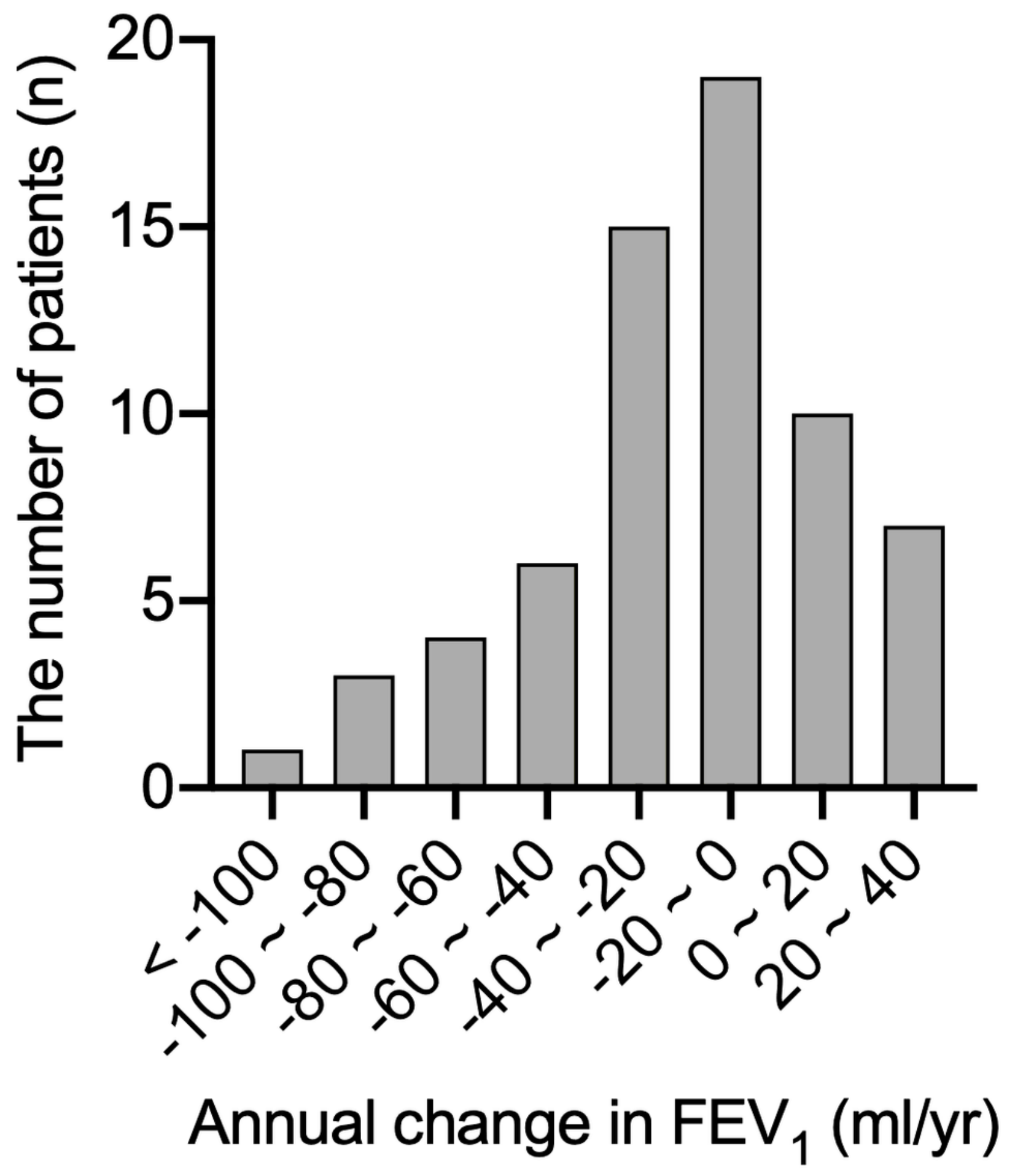

Figure 2

Distribution of annual change in FEV1 in patients with COPD. According to observation over 5 years, the annual change in FEV1 $(\mathrm{mL})$ varied widely. The mean $(\mathrm{SD})$ was $-17.8(32.4) \mathrm{mL} /$ year $(\mathrm{n}=65)$. 
A
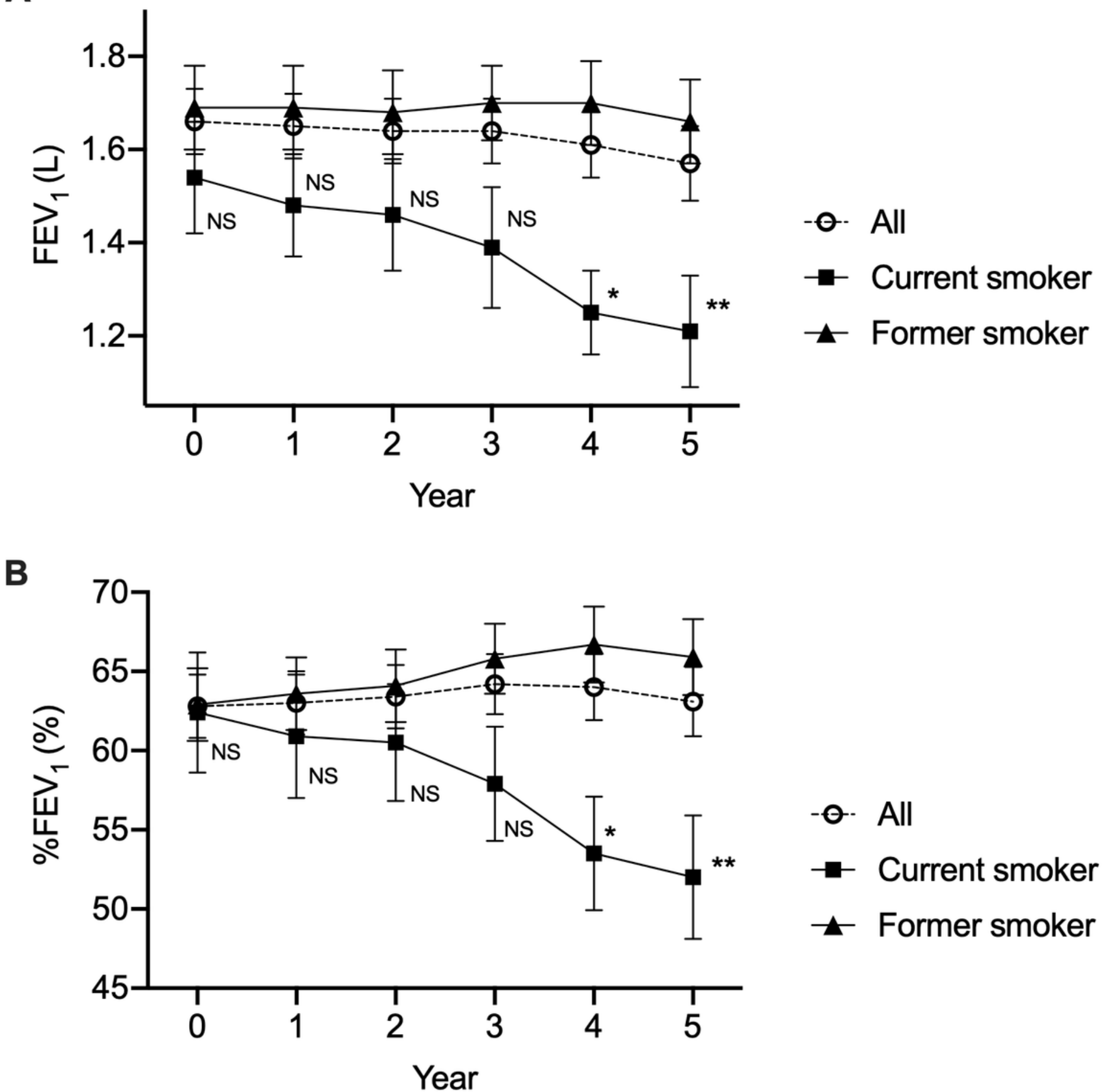

Figure 3

Comparison of FEV1 and \%FEV1 over time between current and former smokers with COPD. There were significant differences in FEV1 (A) or \%FEV1 (B) between current and former smokers both 4 and 5 years after baseline. The bars represent mean \pm standard error of the mean. The differences between current and former smokers were analyzed using unpaired t-tests. NS: not significant, *: $p<0.05,{ }^{\star *} p<0.01$ 

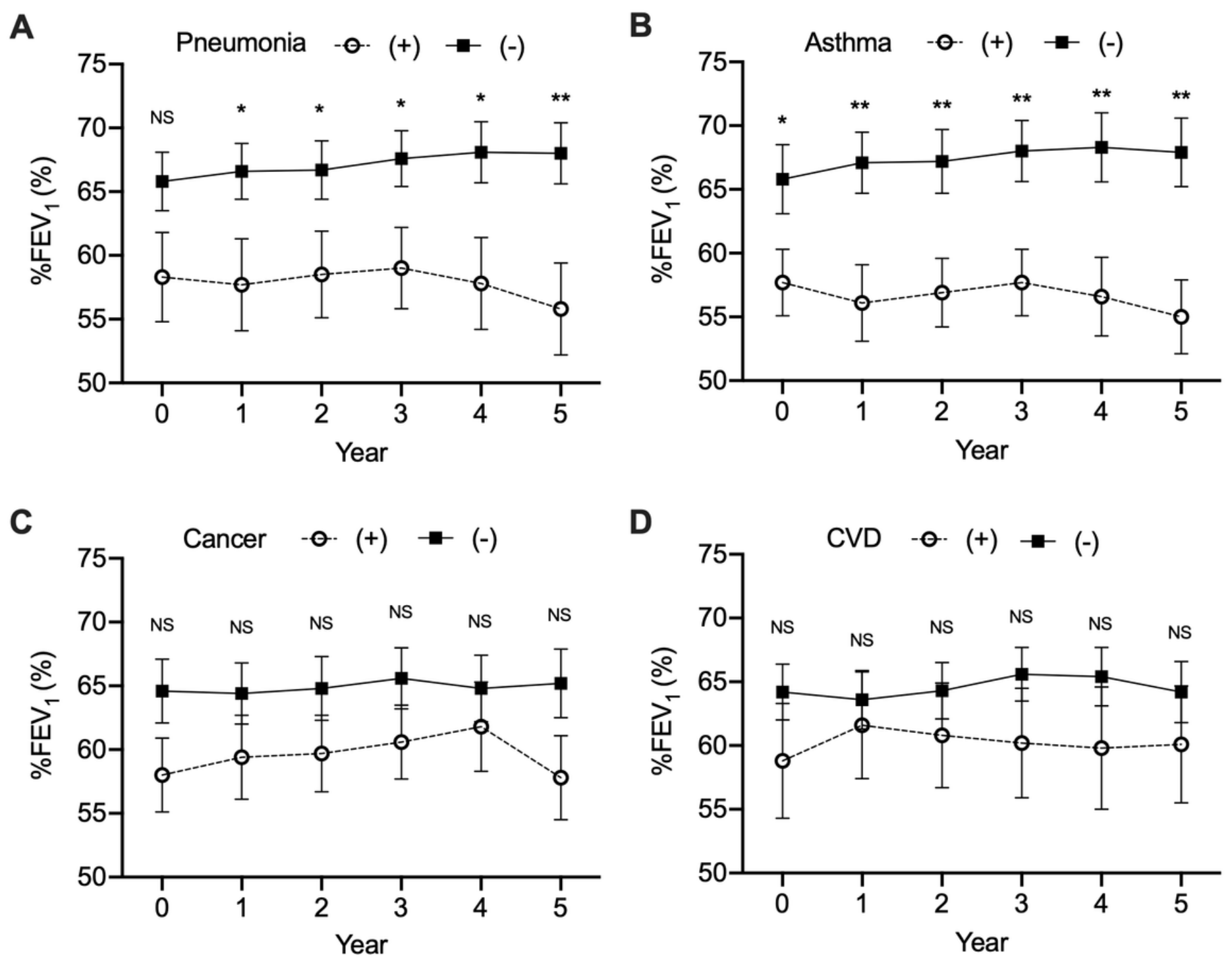

Figure 4

Comparison of \%FEV1 in COPD patients with and without comorbidities. There were significant differences in \%FEV1 in patients with and without pneumonia or asthma but not cancer or cardiovascular disease. The bars represent mean \pm standard error of the mean. The differences between patients with and without each comorbidity were analyzed using unpaired t-tests. NS: not significant, $*$ : $p<0.05, * \star p<$ 0.01

\section{Supplementary Files}

This is a list of supplementary files associated with this preprint. Click to download.

- Table1.jpg

- Table2.jpg

- Table3.jpg 